Study nurses (and coordinators of the trial) were Katrina Agnew, Mardy Bartlett, Jennifer Hodgeman, Karen Lindsey, and Jo Tissier.

Research staff were Wendy Dobbie (research assistant), Godfrey Fowler (reader in general practice, honorary director, joint principal investigator), Alice Fuller (research officer), Lesley Jones (computer scientist), David Mant (clinical lecturer in general practice), Margaret Thorogood (research fellow), and Pat Yudkin (statistician).

Compilers of this report were Pat Yudkin, David Mant, Lesley Jones, and Godfrey Fowler.

Benowitz NL. Pharmacological aspects of cigarette smoking and nicotine addiction. $N$ Engl f Med 1988;319:1318-30.

Lam W, Sze P, Sacks H, Chalmers T. Meta-analysis of randomised controlled trials of nicotine chewing-gum. Lancet 1985; ; 27 .

3 Jamrozik K, Fowler G, Vessey $M$, Wald N. Placebo controlled trial of nicotine chewing gum in general practice. $B M 7$ 1984;289:794-7.

4 Transdermal Nicotine Study Group. Transdermal nicotine for smoking

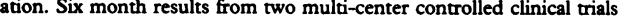
JAMA 1991;266:3133-8.

5 Tonnesen P, Norregaard J, Simonsen K, Sawe U. A double-blind trial of a 16 hour transdermal nicotine patch in smoking cessation. $N$ Engl $f$ Med 1991;325:311-5.

6 Tonnesen P, Norregaard J, Sawe U. Two year outcome in a smoking cessation trial with a nicotine patch. Fournal of Smoking Related Disorders 1992;3 241-5.

7 Abelin T, Buehler A, Muller P, Vesanen K, Imhof PR. Controlled trial of transdermal nicotine patch in tobacco withdrawal. Lancet 1989;i:7-9.

8 Abelin T, Ehrsam R, Imhof P, Muller P. Clinical experience with a transdermal nicotine system in healthy nicotine-dependent smokers. In: Wilhelmsen L, ed. Smoking as cardiovascular risk-new strategies for smoking cessation. Lewiston, New York: Hegrefe and Huber, 1991:35-46.

9 Steele C. Smoker's quit plan. Macclesfield: Gardiner-Caldwell, 1990

10 Jarvis MJ. The classification of smoking behaviour. In: Why children smoke. London: HMSO, 1990:5-11.

11 Jarvis $M$, Russell $M$, Saloojee $Y$. Expired air carbon monoxide: a simple breath test of tobacco smoke intake. $B M 7$ 1980;281:484-5.

12 Russell M, Peto J, Patel W. The classification of smoking by factorial structure of motives. Foumal of the Royal Statistical Society A 1974;137:313-33.

(Accepted 16 February 1993)

\title{
Targeting heavy smokers in general practice: randomised controlled trial of transdermal nicotine patches
}

\section{A H Russell, J A Stapleton, C Feyerabend, S M Wiseman, G Gustavsson, U Sawe, P Connor}

Abstract

Objectives-(a) To evaluate the efficacy of transdermal nicotine patches as an aid to stopping smoking when used as an adjunct to brief advice and support in a general practice setting; (b) to see whether an increase in nicotine patch dosage enhances the rate of initial cessation.

Design-Randomised double blind placebo controlled parallel group study with one year of follow up.

Setting-30 general practices in 15 English counties.

Subjects -600 dependent heavy smokers $(\geqslant 15$ cigarettes daily) who were well motivated to give up.

Interventions-Brief general practitioner advice, booklet, and 16 hours per day patch treatment for 18 weeks with brief support and follow up at one, three, six, 12, 26, and 52 weeks.

Main outcome measures-Self reported complete

Health Behaviour Unit, Institute of Psychiatry, London SE5 8AF

M A H Russell, professor of addiction

J A Stapleton, statistician C Feyerabend, principal biochemist

Department of Primary Health Care, University College and Middlesex School of Medicine, Whittington Hospital, London N19 5NF S M Wiseman, clinical lecturer

\section{Kabi Pharmacia}

Therapeutics AB, Helsingborg, Sweden G Gustavsson, clinical research manager

U Sawe, medical director

Lundbeck UK Ltd, Milton Keynes MK7 8LF

$\mathrm{P}$ Connor, clinical research

manager

Correspondence to:

Professor Russell.

BMF 1993;306: 1308-12

validation at all follow up points.

Results-Nicotine patches reduced the severity of craving and adverse mood changes in the first weeks of withdrawal and doubled the rate of initial cessation at week 3 (nicotine group $36 \%$ of patients (144/ $400)$, placebo group $16.5 \%$ of patients (33/200)) and of continuous abstinence throughout one year (nicotine group 9.3\% (37), placebo group 5.0\% (10)). A dose increase at week 1 among patients experiencing difficulty in quitting increased the proportion who achieved abstinence at week 3 . There were no adverse systemic effects attributable to nicotine, but the incidence of moderate or severe local irritation or itching at the patch site was $16.4 \%$ (63 patients), compared with $3.8 \%$ (seven) with placebo.

Conclusion-Transdermal nicotine patches used as an adjunct to brief advice and support in a general practice setting are an effective aid to long term cessation of smoking in highly dependent smokers.

\section{Introduction}

Cigarette smoking has long been recognised as the major single cause of preventable disease and premature death in developed countries. ${ }^{1}$ According to estimates by Peto et al between a third and a half of smokers will die from smoking if they do not give it up. Those who die aged 35-69 lose an average of 23 years of life. ${ }^{2}$ Although many smokers succeed in stopping without any formal help or treatment, there are many more who fail despite trying hard to stop.

Nicotine replacement therapy with nicotine chewing gum is established as an effective aid to stopping smoking, ${ }^{34}$ and transdermal nicotine patches have recently become available for clinical use in several countries. ${ }^{5}$ A number of placebo controlled trials have shown that nicotine skin patches are effective at reducing craving for cigarettes and increasing the rates of short term cessation ${ }^{6-10}$ but only two, carried out at specialist clinics, have assessed and shown efficacy over a longer term. ${ }^{112}$

It is important to evaluate the patches in general practice, where the efficacy of nicotine gum has been less consistent..$^{43}$ A potential advantage of the skin patch is the ease of securing good compliance with minimal instruction. This makes it suitable for use as an adjunct to brief interventions targeted at many smokers. We report the outcome for up to one year of follow up of the first 600 subjects of a multicentre controlled trial in general practice.

\section{Subjects and methods}

The study was designed to evaluate the efficacy of nicotine skin patches $(a)$ in alleviating withdrawal symptoms, $(b)$ in enhancing initial cessation in the first three weeks of attempting to stop smoking, and $(c)$ in preventing relapse in the first three months after stopping (weeks 3-12) and to examine the overall effect of these factors on increasing the rate of long term cessation for up to one year. Additional aims were to examine the effect of increasing patch nicotine dosage in those who seemed to respond inadequately to the standard dose and to compare the effects of gradual versus abrupt withdrawal of transdermal nicotine on the relapse rate after three months of abstinence from smoking. However, the size of the study sample was determined to address the four main questions and we were aware that statistical power might not be adequate for definitive answers to the two subsidiary points of interest.

The sample size of 1200 was planned to detect differences between the low rates of sustained abstinence expected after one year, and the study had a $95 \%$ chance to detect a difference of $10 \%$ versus $5 \%$ ( $p<0.05$, one sided test). Thus both $\alpha$ and $\beta$ were set at 
$5 \%$. This preliminary report of active and placebo differences in the first 600 subjects had $70 \%$ power to detect such a difference. A one sided test for outcome was regarded as appropriate in view of the consistent evidence from trials of higher success rates in the nicotine replacement condition.

SUBJECTS

A sample of 1200 cigarette smokers was recruited in 30 general practices in 15 English counties, including London. Smokers of either sex, aged between 20 and 60 , who smoked at least 15 cigarettes per day were eligible if their general practitioner considered them to be highly dependent on smoking and well motivated to give it up. Exclusion criteria were the presence of severe cardiovascular disease, hypertension or diabetes, current psychotropic medication, pregnancy or breast feeding, chronic dermatological disorders or history of moderate to severe allergies, and use of nicotine gum in the past three months.

Practices with four or more partners were approached from among those known to representatives of the pharmaceutical company which sponsored and coordinated the trial. In the first instance, out of 60 practices that were sent a letter and brief questionnaire (from MAHR), 14 were recruited that were keen to participate and had adequate facilities, including a practice nurse to help in collecting data and administering treatment. Other practices added were approached by the company direct. Neither the doctors nor nurses received special training in counselling smokers but were encouraged to proceed in their individual way. However, they were briefed fully on the details of the study by clinical research associates of the pharmaceutical company, who also monitored their progress and adherence to the protocol throughout.

\section{NICOTINE PATCH}

The nicotine patch was a $30 \mathrm{~cm}^{2}$ sticking plaster containing $0.83 \mathrm{mg}$ nicotine $/ \mathrm{cm}^{2}$ incorporated into the adhesive layer and which delivered an average of $15 \mathrm{mg}$ (SD $3.5 \mathrm{mg}$ ) nicotine into the bloodstream over 16 hours (manufacturer: Cygnus Research USA; supplier: Kabi Pharmacia, Sweden). Smaller $20 \mathrm{~cm}^{2}$ and $10 \mathrm{~cm}^{2}$ patches delivered about 10 and $5 \mathrm{mg}$ nicotine respectively over 16 hours. ${ }^{14}$ The placebo patches were identical in size and appearance but contained no nicotine. A new patch was applied each morning to a dry, non-hairy area on the upper arm, trunk, buttock, or thigh and removed before going to bed.

\section{STUDY DESIGN}

The study had a double blind, placebo controlled, parallel group design with two thirds of subjects randomly allocated to active patches and one third to placebo patches. After initial screening eligible smokers reattended for a full assessment (week 0 ) before randomisation within practice (fig 1). Subjects nominated a target date for stopping smoking, which was no more than four days after entry to the trial, and started patch use on that day. Further visits for brief support, monitoring, and renewal of patch supplies took place one, three, six, and 12 weeks after starting treatment, with follow up visits after six months and one year.

At one week patients who were still smoking, or experiencing great difficulty abstaining, received a dose increase which entailed wearing an additional, smaller patch for the remainder of the treatment period. Based on randomisation at entry, for those in the active group this additional patch contained nicotine or was a placebo, whereas all eligible subjects in the placebo group received an extra placebo (fig 1).

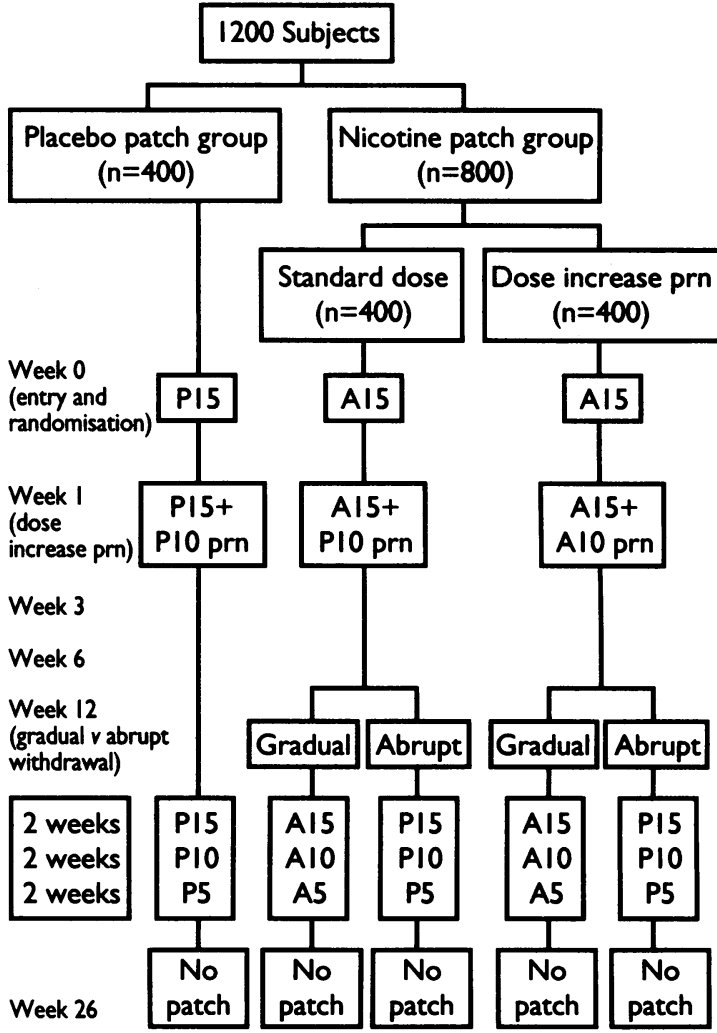

Week 52

$$
\begin{aligned}
& \text { A15 = Standard } 15 \mathrm{mg} \text { nicotine patch } \\
& \text { A10 \& A5 = } 10 \mathrm{mg} \& 5 \mathrm{mg} \text { nicotine patches } \\
& \text { PI5 = Standard size placebo patch } \\
& \text { PI0 \& P5 = Smaller placebo patches } \\
& \text { prn = Dose increase when necessary by wearing additional patch } \\
& \text { (this option at week I only and applicable till week 12) }
\end{aligned}
$$

FIG 1-Study design. All subjects received standard size patch from week 0 with option at week 1 to have additional, smaller patch until week 12. After week 12 single patches of reducing size were given for six weeks

Again both subjects and their doctors or nurses were blind to whether the dose increase was real or placebo. Criteria for offering an extra patch were (a) self report of any lapse (even a puff) on the day of the week 1 visit or the preceding two days, (b) failure of carbon monoxide validation ( $\geqslant 10 \mathrm{ppm}$ ), and (c) abstinent but having great difficulty with little confidence in being able to remain abstinent. This last criterion was left to the clinical judgment of the doctor or nurse. The dose increase option applied only to the week 1 visit, but once initiated it continued to the end of treatment.

A further condition, randomised at entry, was a comparison of gradual versus abrupt withdrawal of transdermal nicotine over six weeks after week 12. A numbered package for each subject contained a full supply of the combination of patches necessary to complete the course, including weaning, but subjects were given supplies at each visit sufficient to last only until the next visit with patches for three days per week to spare. At entry to the study subjects were assigned to treatment according to a computer generated list compiled in blocks of six (four active, two placebo).

\section{MEASURES AND PROCEDURES}

One doctor in each practice served as investigator responsible for coordinating recruitment, treatment, and data collection. The protocol was flexible to enable doctors to recruit subjects opportunistically or from their computerised patient records. Likewise, the extent to which contact and brief support were provided by the doctors or delegated to their nurses could be varied to suit each practice. Although practice teams received no specific guidance on counselling smokers, a six page printed booklet (by MAHR) with information about the patch and how to give up smoking was 
given to each subject and served also to provide the practice teams with essential information.

At assessment (week 0) demographic data were recorded and subjects completed a smoking questionnaire which included measures of their dependence and motivation to stop. ${ }^{15}{ }^{16}$ At week 0 and all subsequent visits measures of expired air carbon monoxide concentration (Bedfont EC50 monitor), body weight, pulse, and blood pressure were taken, a saliva sample was collected for cotinine analysis ${ }^{17}$ and questionnaire measures of withdrawal symptoms ${ }^{15}$ were completed. Data on smoking and patch use since the last visit and ratings of unwanted local and systemic effects of patch use (none, mild, moderate, severe) were collected and the skin examined at week 1 and subsequent visits as appropriate. Subjects were instructed not to use nicotine gum. This and other medications were recorded at each visit.

Subjects were encouraged to make every effort to stop smoking completely from the first day of patch treatment and, if they failed or lapsed, to try even harder after dose increase at week 1 . Those still smoking at week 6 were not pressed to continue patch use, but patches were supplied to subjects who wished to continue.

\section{DETERMINATION OF OUTCOME}

Self reported abstinence at each visit was assessed by the response of subjects to the questionnaire item, "Have you smoked at all since the last visit?" (yes/no). The main criterion of success was self reported complete abstinence from week 3 to one year, validated by a carbon monoxide concentration $<10 \mathrm{ppm}$ at weeks 3 , $6,12,26$, and 52 . Outcome was determined on an intention to treat basis with failure to attend for validation at any point being counted as a lapse to smoking.

\section{STATISTICAL ANALYSES}

Differences between proportions were assessed by the $\chi^{2}$ test and means were compared by $t$ test. Analysis of pretreatment predictors of outcome was carried out by logistic regression. One sided probability levels were used, as planned, to compare abstinence rates. All other comparisons were based on two sided tests.

\section{Results}

Apart from a chance difference in sex distribution, subjects in the active and placebo patch groups were well matched for demographic and smoking characteristics (table I). The measures of smoke intake and dependence were similar to those found among smokers attending specialised clinics, ${ }^{15}{ }^{18}$ reflecting the intention to target the more highly dependent heavy smokers.

TABLE I-Subject characteristics on entry to study

\begin{tabular}{|c|c|c|}
\hline & $\begin{array}{l}\text { Nicotine } \\
\text { patch group } \\
(n=400)\end{array}$ & $\begin{array}{l}\text { Placebo } \\
\text { patch group } \\
(\mathrm{n}=200)\end{array}$ \\
\hline $\begin{array}{l}\text { No }(\%) \text { male } \\
\text { No (\%) with non-manual occupation * } \\
\text { Mean age (years) (SD) } \\
\text { Mean weight (kg) (SD) }\end{array}$ & $\begin{array}{c}142 / 398(35 \cdot 7) \\
163 / 338(48 \cdot 2) \\
39 \cdot 3(9 \cdot 2) \\
69 \cdot 9(14 \cdot 2)\end{array}$ & $\begin{array}{c}89 / 200(44 \cdot 5) \\
85 / 171(49 \cdot 7) \\
39 \cdot 9(9 \cdot 7) \\
70 \cdot 6(15 \cdot 0)\end{array}$ \\
\hline Mean saliva cotinine (SD) $\left\{\begin{array}{l}\mu \mathrm{mol} / \mathrm{l} \\
\mathrm{ng} / \mathrm{ml}\end{array}\right.$ & $\begin{array}{l}2 \cdot 2(1 \cdot 0) \\
381(171)\end{array}$ & $\begin{array}{l}2.1(0.9) \\
375(158)\end{array}$ \\
\hline $\begin{array}{l}\text { Mean expired air carbon monoxide (ppm) } \\
\text { (SD) } \\
\text { Mean No of cigarettes per day (SD) } \\
\text { No (\%) smoking within five minutes of }\end{array}$ & $\begin{array}{l}24 \cdot 6(11 \cdot 9) \\
23 \cdot 4(6 \cdot 8)\end{array}$ & $\begin{array}{l}23 \cdot 7(11 \cdot 6) \\
23 \cdot 6(7 \cdot 6)\end{array}$ \\
\hline $\begin{array}{l}\text { waking } \\
\text { Mean dependence score (SD) } \\
\text { Mean motivation score (SD) }\end{array}$ & $\begin{array}{c}81 / 392(20 \cdot 7) \\
10 \cdot 4(1 \cdot 7) \\
13 \cdot 9(1 \cdot 3)\end{array}$ & $\begin{array}{c}28 / 197(14 \cdot 2 \\
10 \cdot 4(1 \cdot 7) \\
13 \cdot 9(1 \cdot 3)\end{array}$ \\
\hline $\begin{array}{l}\text { No (\%) having made at least one serious } \\
\text { attempt to quit }\end{array}$ & $288 / 388(74 \cdot 2)$ & $146 / 196(7$ \\
\hline $\begin{array}{l}\text { No (\%) having previously quit for more than } \\
\text { three months }\end{array}$ & $49 / 387(12 \cdot 7)$ & $23 / 196(11 \cdot 7)$ \\
\hline
\end{tabular}

*Husband's occupation if subject a housewife.
Outcome-In the active treatment group $36 \%$ of patients (144/400) achieved initial cessation at week 3 compared with $16.5 \%$ of patients $(33 / 200)$ wearing placebo $\left(\chi^{2}=24.4 ; p<0.001\right)$, and $9.3 \%$ of patients in the active group (37) maintained complete abstinence up to one year compared with $5.0 \%$ of placebo treated subjects $(10)\left(\chi^{2}=3.34 ; p=0.034\right)$. This about doubling of the success rate was evident at all follow up points over the year (table II). There was no evidence that active treatment reduced relapse during the treatment period between three weeks and three months, and about half the subjects in each group relapsed during the period. However, active treatment may have contributed to maintenance of the initial advantage gained in the first three weeks. Relapse rates after withdrawal of treatment after three months did not differ significantly in the active and placebo patch groups, nor was there evidence of an effect of abrupt versus gradual withdrawal of transdermal nicotine.

TABLE II-Numbers (percentages) of patients reporting continuous abstinence validated biochemically at all points up to time of follow up

\begin{tabular}{lccc}
\hline $\begin{array}{l}\text { Weeks after } \\
\text { randomisation }\end{array}$ & $\begin{array}{c}\text { Nicotine } \\
\text { patch group } \\
(\mathrm{n}=400)\end{array}$ & $\begin{array}{c}\text { Placebo } \\
\text { patch group } \\
(\mathrm{n}=200)\end{array}$ & $\begin{array}{c}\text { Relative abstinence } \\
\text { rate }(95 \% \\
\text { confidence interval) }\end{array}$ \\
\hline Week 3 & $144(36.0)$ & $33(16.5)$ & $2 \cdot 2(1.6$ to $3 \cdot 1)$ \\
Week 6 & $103(25 \cdot 8)$ & $21(10.5)$ & $2.5(1.6$ to 3.8$)$ \\
Week 12 & $70(17.5)$ & $15(7.5)$ & $2.3(1.4$ to 4.0$)$ \\
Week 26 & $50(12.5)$ & $13(6.5)$ & $1.9(1.1$ to 3.5$)$ \\
Week 52 & $37(9.3)$ & $10(5.0)$ & $1.9(1.0$ to 3.6$)$ \\
\hline
\end{tabular}

Effect of dose increase-Of 567 patients who attended at week $1,48 \%(184 / 383)$ in the active treatment group and $68 \%(126 / 184)$ of those receiving placebo were given a dose increase to two patches per day. The higher proportion of placebo treated subjects given an extra patch $\left(\chi^{2}=21.0 ; p<0.001\right)$ indicates that they were having more problems with quitting. Among patients in the active treatment group who received a real dose increase, $25 \cdot 3 \%(24 / 95)$ were abstinent at week 3 compared with $14.6 \%(13 / 89)$ of those in whom the extra patch was a placebo $(p=0.04)$. Thus the dose increase significantly enhanced initial cessation compared with continuation with standard dosage. There was evidence that this effect was diminished at later follow up visits, but statistical power was inadequate for testing this further.

Compliance-Self reports of compliance with patch use on at least six days of the past week declined steadily over successive follow up visits but did not differ greatly between active and placebo patch groups. Among those who attended for each follow up visit, compliance rates in the active and placebo patch groups were: week 1, 91\% (282/310) v 86\% (133/155) $(p=0.09)$; week 3, 73\% (199/272) v62\% (75/121) $(\mathrm{p}=0.03)$; week 6, 67\% (137/203) v 63\% (40/63); and week 12, 59\% (81/138) v 54\% (19/35).

Withdrawal symptoms-Analysis of withdrawal symptoms and craving was confined to patients who were abstinent or controlling their smoking sufficiently to register a carbon monoxide value below $10 \mathrm{ppm}$. Both craving and adverse mood changes were significantly less severe over the first few weeks in the group having active treatment (table III). Apart from craving, subjects having active treatment experienced little withdrawal discomfort, and their ratings of mood changes and difficulty with concentration differed only slightly from baseline in the first few weeks. There was no evidence of greater sleep disturbance in patients on active treatment compared with those in the placebo group. Weight gain in subjects who had been continuously abstinent for up to 12 weeks was not significantly reduced by active treatment and averaged 3.6 (SD 2.9) kg compared with $3.4(2.5) \mathrm{kg}$ in those receiving placebo. 
TABLE $\mathrm{II}-$ Mean mood and craving scores in nicotine and placebo patch subjects during first 12 weeks of trying to quit smoking

\begin{tabular}{lccccc}
\hline & \multicolumn{2}{c}{ Nicotine patch group } & & \multicolumn{2}{c}{ Placebo patch group } \\
\cline { 2 - 3 } \cline { 5 - 6 } $\begin{array}{l}\text { Weeks after } \\
\text { randomisation }\end{array}$ & $\begin{array}{c}\text { Mean score } \\
\text { (SD) }\end{array}$ & $\begin{array}{c}\text { No } \\
\text { studied }\end{array}$ & & $\begin{array}{c}\text { Mean score } \\
\text { (SD) }\end{array}$ & $\begin{array}{c}\text { No } \\
\text { studied }\end{array}$ \\
\hline \multicolumn{5}{c}{$\begin{array}{l}\text { Mood scores (change from baseline) } \dagger \\
1\end{array}$} \\
3 & $0.21(0.93)^{\star \star}$ & 246 & & $0.58(0.85)$ & 89 \\
6 & $0.17(0.91)^{\star}$ & 222 & & $0.50(0.90)$ & 67 \\
12 & $0.03(0.93)$ & 167 & & $0.21(0.88)$ & 41 \\
& $-0.13(0.96)$ & 115 & & $0.07(0.62)$ & 27
\end{tabular}

Craving scorest

\begin{tabular}{rllll}
1 & $1.74(0.97)^{\star \star}$ & 244 & $2.17(0.93)$ & 89 \\
3 & $1.44(0.95)^{\star \star}$ & 222 & $2.02(0.99)$ & 67 \\
6 & $1.19(0.98)$ & 167 & $1.43(0.96)$ & 41 \\
12 & $0.94(0.94)$ & 115 & $0.85(0.65)$ & 27 \\
\hline
\end{tabular}

Compared with placebo group ${ }^{\star} \mathrm{p}<0.01,{ }^{\star \star} \mathrm{p}<0.001$ ( $t$ test)

Compl score was derived for each subject at each visit, comprising mean of †Mood score was derived for each subject at each visit, comprising mean of questionnaire items relating to depression, irritability, restlessness, tension, anxiety, and poor concentration. Graving score was derived from items on craving for cigarettes, difficulty not smoking, frequency of urges to smoke, and strength of urges. All items were scored on scales from 0 (not at all) to 4 (extremely).

Side effects-Analysis of side effects was based on all subjects (383 wearing active patches, 184 wearing placebo) who provided ratings at least once. The incidence of the most frequent systemic symptoms did not differ in the active and placebo treatment groups. Reports of "moderate" or "severe" symptoms in the two groups were: nausea (4.2\% (16 patients) $v 4 \cdot 9 \%$ (nine)), headache $(12 \%(46) v 9 \%(17))$, and lightheadedness $(7 \%$ (25) $v 8 \%(15))$. However, local irritation and itching at the patch sight were more common with the active patch. The incidences of moderate or severe effects in the active and placebo conditions were: local erythema $7 \cdot 0 \%$ (27 cases) $v 1 \cdot 6 \%$ (three) $(\mathrm{p}<0.01)$, urticaria or vesiculation $3.7 \%$ (14) $v$ $1 \cdot 6 \%$ (three) $(\mathrm{p}=0 \cdot 19)$, oedema $2 \cdot 1 \%$ (eight) $v$ zero $(\mathrm{p}=0.06)$, and itching $16.4 \%$ (63) $v 3.8 \%$ (seven) $(p<0.001)$. Active patches were discontinued in eight $(2.0 \%)$ subjects on account of unwanted effects-skin reactions in six cases, pain in the patch bearing arm in one, and "intermittent blurred vision" in one. Patches were also withdrawn in three $(1.5 \%)$ placebo treated subjects (one for severe nausea, one for skin reaction, and one for severe lightheadedness and fainting).

Pretreatment predictors of abstinence-The effect of pretreatment characteristics on the likelihood of achieving continuous abstinence for up to 12 weeks was assessed by logistic regression adjusted for treatment allocation. Neither age nor sex nor occupation nor baseline cigarette consumption nor motivation score had any detectable effect on outcome. Duration of previous abstinence $(p<0.02)$, number of previous attempts to quit $(p<0.03)$, dependence score $(p<0.04)$, expired air carbon monoxide level $(p<0.05)$, and saliva cotinine concentration $(p=0.02)$ each had a small but significant effect. The strongest predictor was the dependence item, time to first cigarette of the day $(p<0.01)$. Only $23 \%(137 / 589)$ of subjects studied waited over 30 minutes for their first cigarette. Of these, $20 \%(27 / 137)$ were abstinent for 12 weeks, as compared with only $9 \%(10 / 109)$ of those who lit up within five minutes (fig 2). There were no interactions between predictors and treatment condition.

\section{Discussion}

Nicotine patch treatment significantly reduced the severity of craving and adverse mood changes in the early stages of cigarette withdrawal and roughly doubled the rate of continuous abstinence for up to one year. The magnitude of the effect was similar to that recorded in other transdermal nicotine studies. ${ }^{5-12}$ However, our study provides clear evidence that nicotine patch treatment is effective as an aid to cessation of smoking for up to one year when used as an adjunct to brief advice and support in a general practice setting. Indeed, of all the studies published to date, ${ }^{5}$ only one-carried out in a hospital setting - showed a statistically significant difference between active treatment and placebo at one year..$^{12}$

The main impact of the nicotine patch was to increase initial cessation during the first three weeks, and this effect was significantly enhanced by the dose increase among patients who had difficulty during the first week. The positive dose-response effect confirms findings of an earlier study in which the dose variation was not blind. " There was no evidence that nicotine patch treatment reduced relapse after initial cessation, although it may have been necessary for maintaining the initial advantage gained. Among those who had stopped smoking at week 3 , relapse rates were similar in the active and placebo treatment groups, about half the initial abstainers in each group relapsing by week 12.

In general, success rates of interventions to help people stop smoking are related to the amount of face to face attention and support provided. As an adjunct to intensive clinic treatment the nicotine skin patch gave a net increase in success rate of $14 \%$ after six months ( $26 \%$ of patients given active treatment, $12 \%$ of patients given placebo) in one study. " However, the amount of behavioural support entailed 45-60 minute group sessions weekly for six weeks and biweekly sessions for a further six weeks, as well as biweekly or monthly follow up visits from three to six months. General practitioners with a special interest who choose to provide more intensive support could expect to get similar results, but we have argued that most general practitioners could help more of their patients become ex-smokers by applying brief intervention to many smokers rather than intensive help for a few. ${ }^{19}$

Brief advice together with a leaflet and warning of follow up given opportunistically by general practitioners to all smokers who attend their surgeries has a net increase over non-intervention of $4-5 \%$ of patients who stop smoking and remain abstinent for one year. ${ }^{19}$ However, those who respond to advice alone are mainly light smokers who average fewer than 10 cigarettes per day. The aim of our study was to target dependent heavy smokers to see whether use of nicotine patches as an adjunct to brief advice and support enables general practitioners effectively to help in these more difficult cases. Our sample of doctors came from a wide range of typical practices and received no special training. The net gain in success rate of $4-5 \%$ for active over placebo treatment at one year would be of enormous potential benefit if widely realised.

In conclusion, our results provide clear evidence that nicotine skin patches, used as an adjunct to brief advice and support in a general practice setting, are a safe and effective aid to stopping smoking in highly dependent but well motivated heavy smokers who are unlikely to succeed with advice and counselling alone. A dose increase in those having difficulty seems to enhance the rate of initial cessation. The $4-5 \%$ net gain over placebo treatment in long term cessation in heavy smokers offers scope for more effective targeting of intervention in primary care-that is, brief advice and support for light smokers, with the addition of nicotine patches for well motivated people who smoke over 10 cigarattes daily. Higher success rates might be obtained by doctors who give more intensive support, but we believe that more ex-smokers would be created by giving brief help to many smokers.

The following general practitioners served as investigator for their practice: $\mathbf{R}$ M Babinskyi (Herts), R H Bawden (Norfolk), M Butteriss (Beds), N Chakrabarti (W Yorks), P D Clifford (Northants), M Colebrook (Beds), P J Dawson (Lincs), A Dellow (Bucks), A D R Disher (Beds), J B Frazer 
(W Yorks), S D Gunn (Lancs), P C Heaney (Northants), W T Irish (Somerset), $S$ Janikiewicz (Wirral), A K Kapur (Beds), C Lewis (Surrey), C L Murphy (London N10), P M Murphy (Suffolk), J K Oldring (Leics), O B O'Toole (Beds), D G Parry (Wirral), T Pinker (Surrey), V A Pizura (Berks), J Rickerby (Northants), M Slattery (Herts), G W Stead (W Yorks), R E S Tripney (Northants), P Wilkinson (Beds), $S$ Wiseman (London N1), A J Wright (Lancs).

This study was funded by Kabi Pharmacia AB, Sweden, which also supervised and monitored procedures and data collection in the practices. We thank the Medical Research Council and Imperial Cancer Research Fund for financial support of the health behaviour unit. The unit's staff designed the study; analysed and wrote up the results, and assayed saliva cotinine concentrations. Our colleague Martin Jarvis gave helpful comments on the manuscript.

1 Royal College of Physicians. Smoking and health now. London: Pitman medical, 1971.

2 Peto R, Lopez AD, Boreham J, Thun M, Heath C. Mortality from tobacco in developed countries: indirect estimation from national vital statistics. Lancet 1992;339:1268-78.

3 Jarvis MJ, Russell MAH. Treatment for the cigarette smoker. Intermational Review of Psychiatry 1989;1:139-47.

4 Lam W, Sze PC, Sachs HS, Chalmers TC. Meta-analysis of randomized controlled trials of nicotine chewing gum. Lancet 1987;ii:27-9.

5 Palmer KJ, Buckley MM, Foulds D. Transdermal nicotine: a review. Drugs 1992;44:498-529.

6 Abelin T, Beuhler A, Muller P, Versanen K, Imhof PR. Controlled trial of transdermal nicotine patch in tobacco withdrawal. Lancet 1989;i:7-10.

7 Mulligan SC, Masterson JG, Devane JG, Kelly JG. Clinical and pharma- cokinetic properties of a transdermal nicotine patch. Clin Pharmacol Ther 1990;47:331-7

8 Rose J, Levin ED, Behm FM, Adivi C, Schur C. Transdermal nicotine facilitates smoking cessation. Clin Pharmacol Ther 1990;47:323-30.

9 Hurt RD, Langer GE, Offord KP, Kottke TE, Dale LC. Nicotinereplacement therapy with use of a transdermal nicotine patch: a randomized double-blind placebo-controlled trial. Mayo Clin Proc 1990;65:1529-37.

10 Daughton DM, Heatly SA, Prendergast JJ, Causey D, Knowles M, Clyde N, et al. Effect of transdermal nicotine delivery as an adjunct to lowintervention smoking cessation therapy. Arch Interm Med 1991;151:749-52.

11 Transdermal Nicotine Study Group. Transdermal nicotine for smoking cessation: six-month results from two multicenter controlled clinical trials. cessation: six-month results

12 Tonnesen $P$, Norregaard J, Simonsen $K$, Sawe U. A double-blind trial of a 16 hour transdermal nicotine patch in smoking cessation. $N$ Engl $f$ Med 1991;325:311-5.

13 Hughes JR, Gust SW, Keenan RM, Fenwick JW, Healey ML. Nicotine vs placebo gum in general medical practice. $¥ A M A$ 1989;261:1300-5.

14 Kabi Pharmacia Research Department. Repon No 19907F. Helsingborg, Sweden: Kabi Pharmacia, 1990.

15 West R, Russell MAH. Preabstinence smoke intake and smoking motivation as predictors of severity of cigarette withdrawal symptoms. Psychopharma cology 1985;86:334-6.

16 Jackson PH, Stapleton JA, Russell MAH, Merriman RJ. Predictors of outcome in general practitioner intervention against smoking. Prev. Med 1986;15:244-53.

17 Feyerabend C, Russell MAH. A rapid gas-liquid chromatographic method for determination of cotinine and nicotine in biological fluids. $f$ Pharm Pharmacol 1990;102:450-2.

18 Sutherland G, Stapleton JA, Russell MAH, Jarvis MJ, Hajek P, Belcher M et al. Randomised controlled trial of nasal nicotine spray in smoking cessation. Lancet 1992;340:324-8.

19 Russell MAH, Wilson C, Taylor C, Baker CD. Effect of general practitioners' advice against smoking. $B M \mathcal{F}^{1979 ; i i: 231-5 .}$

(Accepred 8 April 1993)

\section{RETROSPECT}

\section{Ten years is a long time in general practice}

This month marks the tenth anniversary of my north London practice, a time to take stock and realise what a lot of changes have been crammed into a brief decade. Some are for the better. I have not seen a case of measles for four years, although there were a dozen or so every year before the measles, mumps, and rubella vaccine. I also hope that the reason we have not seen a case of cervical carcinoma for five years may be that well over $80 \%$ of our women patients have smears every three years.

Other innovations appreciated by our patients are not of our making; keyhole surgery is expanding in so many fields that day surgery is becoming routine. Even some ectopic pregnancies can be treated without a laparotomy, and women with menorrhagia are offered hysteroscopic ablation instead of hysterectomy. Lasers can obliterate unsightly birthmarks, though not, in this cost limited world, tattoos. And on the medical side the outlook for patients with peptic ulcer, myocardial infarcts, and heart failure has been transformed by new drugs.

The practice population has changed a good deal too Originally my senior partner and I had around 3000 patients. Now we have nearly 11000 patients, six partners, and a trainee. Until recently our list was cosmopolitan but predominantly middle class. Then the council converted some large Edwardian houses into short stay accommodation and large numbers of refugees arrived. First 50 or so Tamils, 13 of whom memorably caught chicken pox within a month of their arrival. Then waves of Iranians, Kurds, Ethiopians, Somalis, and Sudanese.

It is families like these, arriving penniless in a strange country, who can benefit from a good health visitor or social worker. But funding for these services has been cut to the bone. We used to see a social worker regularly at our weekly practice meeting. But now they have become an endangered species, rarely sighted, and hard to track down. Our plans for an attached health visitor may come to nothing.

Many of the requirements of the general practice contract are a time consuming nuisance. Our expensive computer churns out reams of paper to prove that we are reaching our targets and, in an area of high mobility, our income is constantly threatened by the arrival of an unvaccinated child nearly 2 years old. We are sceptical of the value of regular health checks, though we have always invited new patients in for a consultation, as their notes still take around a year to reach us, even in this computerised age. But our existing patients with asthma or menopausal symptoms resist attempts to make them come in for special clinics. It is irritating that the new contract rewards the general practitioners who do well at easily measurable tasks of doubtful validity rather than the intangible art and science of doctoring.

But we have managed to live with the contract. Where we feel powerless is with the decline of the hospital services. We look back to the golden age of five years ago when a patient with an unusual condition could be referred to a teaching hospital in any part of London without benefit of an extracontractual referral. Waiting lists for outpatients used to be a maximum of two or three months, and there was never any difficulty in getting emergency admissions to our local hospital. How different it is now. Most urgent cases have to be referred through the Emergency Bed Service and some patients have ended up in hospitals several miles away.

We can see the appeal of fundholding as a way of regaining control, but we do not like the two tier system or relish the strain that organising our own budget would put on us and our excellent practice manager. Not so long ago we filled in our claim forms, sent them off to the family practitioner committee, and got on with our work in the hope and expectation that we would end up with a reasonable income. Now we have accounts on computer spread sheets and business plans. The future is not easy to plan when the goal posts are moved so frequently. We can only hope that there will be fewer changes in our second decade than our first.-MARGARET SAFRANER is a general practitioner in London

We welcome contributions to fillers: $A$ patient who changed my practice; $A$ paper that changed my practice; $A$ memorable patient; The message I would most like to leave behind, or similar topics. 